\title{
Microarray analysis of microRNA expression patterns in the semen of infertile men with semen abnormalities
}

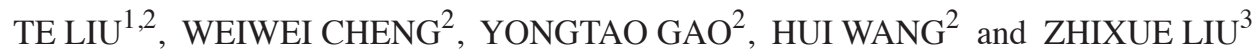 \\ ${ }^{1}$ School of Environmental Science and Engineering, Donghua University, Shanghai 201620; \\ ${ }^{2}$ International Peace Maternity and Child Health Hospital, Shanghai Jiaotong University, Shanghai 200030; \\ ${ }^{3}$ School of Life Science and Technology, Tongji University, Shanghai 200092, P.R. China
}

Received April 6, 2012; Accepted June 18, 2012

DOI: $10.3892 / \mathrm{mmr} .2012 .967$

\begin{abstract}
RNAs (miRNAs) play a crucial role in tissue development and the pathology of many diseases, however, the effects and roles of miRNAs in the development of semen abnormalities in infertile males have not yet been investigated. In this study, we analyzed and compared the miRNA expression profiles of abnormal semen from 86 infertile males with normal semen from 86 healthy males using an miRNA microarray. In total, 52 miRNAs were differentially expressed between the abnormal semen of infertile males and the normal semen of healthy males. The differential expression of selected miRNAs was validated by real time qRT-PCR and northern blotting: miR-574-5p, miR-297, miR-122, miR-1275, miR-373, miR-185 and miR-193b were upregulated (fold change $>1.5, \mathrm{p}<0.001$ ) and miR-100, miR-512-3p, miR-16, miR-19b, miR-23b and miR-26a were downregulated (fold change $<0.667, \mathrm{p}<0.001$ ) in the semen of infertile males with semen abnormalities. In conclusion, this study provides new insights into specific miRNAs that are associated with semen abnormalities in infertile males.
\end{abstract}

\section{Introduction}

Semen abnormalities are a form of male infertility which present in a variety of ways and may prevent the sperm from achieving fertilization (1-4). Previous studies have shown that there are several causes of abnormal semen, including infection with sexually transmitted diseases (STDs), retrograde ejaculation and an inability of the ejaculate to clot properly,

Correspondence to: Dr Te Liu, School of Environmental Science and Engineering, Donghua University, 2999 North Renmin Road, Shanghai 201620, P.R. China

E-mail: liute79@yahoo.com

Dr Zhixue Liu, School of Life Science and Technology, Tongji University, Shanghai 200092, P.R. China

E-mail: liuzhixue@163.com

Key words: abnormal semen, microRNA, microarray, differential expression, male infertility all of which can significantly affect male fertility. In addition, sperm abnormalities may be inherited or due to a hormone imbalance, medication or previous infection (5). Narayana et al indicated that O,O-dimethyl O-4-nitrophenyl phosphorothioate could affect the sperm morphology and count in rats (6), and Padmalatha Rai et al demonstrated that the anticancer drug tamoxifen citrate acts as a germ cell mutagen by inducing sperm shape abnormalities in mice in vivo (7). Additionally, Calogero et al reported that a large proportion of patients with oligoasthenoteratozoospermia and teratozoospermia have an increased rate of sperm aneuploidy, and these patients also have semen abnormalities (8). Studies have also indicated that abnormal semen characteristics are induced by testicular cancer $(9,10)$. Although a number of the factors which cause abnormal semen, including chemotherapeutic agents, testicular tumors and microwave radiation $(5,11,12)$ have been identified, differences in epigenetic regulation between normal and abnormal sperm have not been fully investigated.

microRNAs (miRNAs) are a class of naturally occurring single-stranded short 21-23 nt non-coding RNAs $(13,14)$ which exist in a wide range of eukaryotic organisms (13-18). Each mammalian miRNA can prevent the translation of a number of downstream target mRNAs and ultimately lead to the inhibition of target gene expression $(19,20)$. Therefore, a shift away from the targeting of crucial target genes towards miRNA interference techniques may improve the effectiveness of current gene-based diagnostic and therapeutic strategies (15). However, most miRNA studies have focused on the growth and development of stem cells, differentiation, tumorigenesis and other pathological processes $(19,20)$ and have given little consideration to the role of miRNAs in the development of abnormal semen and male infertility.

Several methods, including northern blot analysis, cloning and sequencing strategies, Invader assays, qRT-PCR and sequencing-based assays have been used to determine the expression of miRNAs in biological samples (21). However, miRNA microarrays have become the method of choice for global miRNA profiling studies, as large numbers of molecules can be screened simultaneously using a flexible probe design strategy (21). Additionally, miRNA microarrays provide a powerful tool for the analysis of miRNA expression patterns and quantitative miRNA expression levels. Microarray technology has become the most commonly utilized miRNA 
research tool, as it is more efficient than time-consuming traditional methods (22-27).

In this study, we used a miRNA microarray-based high throughput approach to identify and quantify the miRNAs that were differentially expressed between the total RNA isolated from the normal semen from healthy males and the abnormal semen from infertile males. The identification of differentially expressed miRNAs in the abnormal semen of infertile males may support further studies to elucidate the causes and characteristics of abnormal semen.

\section{Materials and methods}

Patients. The present study involved 86 infertile males (B) with abnormal semen and 86 normal healthy adult males $(\mathrm{H})$ as the control. The samples were collected from the inpatient clinic of the International Peace Maternity and Child Health Hospital of the China Welfare Institute (Shanghai, China) between February and September 2010. All human materials were obtained according to consent regulations and approved by the Ethical Review Committee of the World Health Organization Collaborating Center for Research in Human Reproduction in Shanghai, China as authorized by the Shanghai Municipal Government. Due to material limitations, we could only analyze a limited number of severely abnormal sperm samples.

Semen collection and assessment of semen function. Semen samples were produced by masturbation, collected in sterile containers and immediately transported to the laboratory. A conventional semen profile was obtained for each sample using the procedures described by the World Health Organization (10).

Total RNA extraction. Total RNA was isolated from each semen sample using the TRIzol reagent (Invitrogen Life Technologies, Carlsbad, CA, USA) according to the manufacturer's instructions $(28,29)$. The RNA samples were treated with DNase I (Sigma-Aldrich, St. Louis, MO, USA) and then quantified.

miRNA microarray analysis. RNA labeling and hybridization were performed on miRNA microarray chips as previously described $(25,27,30)$. Briefly, $50 \mu \mathrm{g}$ of total RNA was purified using the mirVana miRNA isolation kit (Ambion, Austin, TX, USA) to enrich the small RNA fraction. The purified RNA was labeled with fluorescein and hybridized using the CapitalBio mammalian miRNA array V3.0 (CapitalBio Corporation, Beijing, China) containing 2844 mature miRNA gene oligonucleotide probes in triplicate, corresponding to 1823 human, 648 mouse and 373 rat miRNAs. Each individual's semen RNA was analyzed on a separate chip. Finally, scanned images of the microarray were captured and the hybridization signals were quantified. The signal intensity values were normalized to per-chip mean values.

Total RNA extraction and reverse transcription into cDNA. Following the detection of total RNA, we used a Poly(A) Tailing kit (Ambion) to add a poly(A) tail to the RNA products according to the kit's instructions. The RNA samples were treated with DNase I, quantified and reverse-transcribed into cDNA using the ReverTra Ace- $\alpha$ First Strand cDNA Synthesis kit (Toyobo, Osaka, Japan). Notably, this reverse transcription reaction uses the oligo(dT) reverse transcription primer 5'-GCTGTCAACGATACGCTACCTAACGGCATGACAGT GTTTTTTTTTTTTTTT(C/G/A)-3'. All reaction steps were carried out according to the manufacturer's instructions.

Quantitative real-time PCR validation miRNA expression. In accordance with the manufacturer's instructions and as previously described (23), qRT-PCR was conducted in the realplex ${ }^{4}$ real-time PCR detection system from Eppendorf (Hamburg, Germany), using SYBR ${ }^{\circledR}$ Green RealTime PCR Master mix (Toyobo) as the detection dye. The qRT-PCR amplification process comprised 40 cycles of denaturation at $95^{\circ} \mathrm{C}$ for $10 \mathrm{sec}$ and annealing at $57^{\circ} \mathrm{C}$ for $20 \mathrm{sec}$. The target cDNA was quantified using a relative quantification method. A comparative threshold cycle $(\mathrm{Ct})$ was used to quantify the gene expression relative to the control (calibrator). The steady-state mRNA levels were expressed as an n-fold difference relative to the calibrator. For each sample, the $\mathrm{Ct}$ values were normalized using the formula: $\Delta \mathrm{Ct}=\mathrm{Ct}_{\text {miRNA }}-\mathrm{Ct}_{18 \mathrm{~S} \text { rRNA}}$. To detemine relative expression levels, the following formula was used: $\Delta \Delta \mathrm{Ct}=\Delta \mathrm{Ct}_{\mathrm{B}}-\Delta \mathrm{Ct}_{\mathrm{H}}$. The values used to plot the relative miRNA expression levels were calculated using the expression $2^{-\Delta \Delta \mathrm{Ct}}$. The miRNA levels were calibrated by $18 \mathrm{~S}$ rRNA. The miRNA primers used in the cDNA amplification are shown in Table I.

Northern blot analysis. All steps in the northern blotting process were carried out as previously described $(28,29)$. For all samples, $20 \mu \mathrm{g}$ good quality total RNA was analyzed on a $7.5 \mathrm{M}$ urea $12 \%$ PAA denaturing gel and transferred to a Hybond-N+ nylon membrane (Amersham, Freiburg, Germany). The membranes were crosslinked using UV light for $30 \mathrm{sec}$ at $1200 \mathrm{~mJ} / \mathrm{cm}^{2}$. Hybridization was performed using miRNA antisense StarFire probes to detect the 22-nt miRNA fragments, according to the manufacturer's instructions. After washing, the membranes were exposed for 20-40 h to Kodak XAR-5 films (Sigma-Aldrich). The ethidium bromide-stained gels prior to the transfer of tRNA were used as controls to ensure equal loading of the RNA samples.

Statistical analysis. Each experiment was performed at least three times and data are the mean \pm SE, where applicable. Differences were evaluated using the Student's t-test. $\mathrm{p}<0.05$ was considered to indicate a statistically significant result.

\section{Results}

Comparison of the characteristics and semen parameters of the healthy males and infertile males. A total of 172 males were invited to participate in this study: 86 healthy males with normal semen and 86 infertile males with semen abnormalities. The only significant difference between the populations was the percentage of progressive motile $(a+b)$ forms $(p<0.001)$. The results of laboratory tests indicated that asthenozoospermia was the most frequent finding in the 86 infertile males. The characteristics of the study participants are presented in Table II. 
Table I. The miRNA qRT-PCR primers used in the study.

\begin{tabular}{|c|c|c|}
\hline Accession no. & miRNA & qRT-PCR primers $\left(5^{\prime} \rightarrow 3^{\prime}\right)$ \\
\hline MI0003581 & $\operatorname{miR}-574-5 p$ & $\begin{array}{l}\text { 5'-TGAGTGTGTGTGTGTGAGTGTGT-3' (forward) } \\
\text { 5'-GCTGTCAACGATACGCTACCTA-3' (reverse) }\end{array}$ \\
\hline MI0000063 & let-7b & $\begin{array}{l}\text { 5'-CTATACAACCTACTGCCTTCCC-3' (forward) } \\
\text { 5'-GCTGTCAACGATACGCTACCTA-3' (reverse) }\end{array}$ \\
\hline MI0005775 & miR-297 & $\begin{array}{l}\text { 5'-ATGTATGTGTGCATGTGCATG-3' (forward) } \\
\text { 5'-GCTGTCAACGATACGCTACCTA-3' (reverse) }\end{array}$ \\
\hline MI0000442 & miR-122 & $\begin{array}{l}\text { 5'-AACGCCATTATCACACTAAATA-3' (forward) } \\
\text { 5'-GCTGTCAACGATACGCTACCTA-3' (reverse) }\end{array}$ \\
\hline MI0006415 & $\operatorname{miR}-1275$ & $\begin{array}{l}\text { 5'-GTGGGGGAGAGGCTGTC-3' (forward) } \\
\text { 5'-GCTGTCAACGATACGCTACCTA-3' (reverse) }\end{array}$ \\
\hline MI0006428 & miR-1281 & $\begin{array}{l}\text { 5'-TCGCCTCCTCCTCTCCC-3' (forward) } \\
\text { 5'-GCTGTCAACGATACGCTACCTA-3' (reverse) }\end{array}$ \\
\hline MI0000781 & $\operatorname{miR}-373$ & $\begin{array}{l}\text { 5'-GAAGTGCTTCGATTTTGGGGTGT-3' (forward) } \\
\text { 5'-GCTGTCAACGATACGCTACCTA-3' (reverse) }\end{array}$ \\
\hline MI0000482 & $\operatorname{miR}-185$ & $\begin{array}{l}\text { 5'-AGGGGCTGGCTTTCCTCTGGTC-3' (forward) } \\
\text { 5'-GCTGTCAACGATACGCTACCTA-3' (reverse) }\end{array}$ \\
\hline MI0003137 & $\operatorname{miR}-193 b$ & $\begin{array}{l}\text { 5'-AACTGGCCCTCAAAGTCCCGCT-3' (forward) } \\
\text { 5'-GCTGTCAACGATACGCTACCTA-3' (reverse) }\end{array}$ \\
\hline MI0000461 & miR-145 & $\begin{array}{l}\text { 5'-GGATTCCTGGAAATACTGTTCT-3' (forward) } \\
\text { 5'-GCTGTCAACGATACGCTACCTA-3' (reverse) }\end{array}$ \\
\hline MI0000290 & $\operatorname{miR}-214$ & $\begin{array}{l}\text { 5'-ACAGCAGGCACAGACAGGCAGT-3' (forward) } \\
\text { 5'-GCTGTCAACGATACGCTACCTA-3' (reverse) }\end{array}$ \\
\hline MI0000089 & $\operatorname{miR}-31$ & $\begin{array}{l}\text { 5'-TGCTATGCCAACATATTGCCAT-3' (forward) } \\
\text { 5'-GCTGTCAACGATACGCTACCTA-3' (reverse) }\end{array}$ \\
\hline MI0003513 & $\operatorname{miR}-455-3 p$ & $\begin{array}{l}\text { 5'-GCAGTCCATGGGCATATACAC-3' (forward) } \\
\text { 5'-GCTGTCAACGATACGCTACCTA-3' (reverse) }\end{array}$ \\
\hline MI0000102 & $\operatorname{miR}-100$ & $\begin{array}{l}\text { 5'-CAAGCTTGTATCTATAGGTATG-3' (forward) } \\
\text { 5'-GCTGTCAACGATACGCTACCTA-3' (reverse) }\end{array}$ \\
\hline MI0003161 & $\operatorname{miR}-517 a$ & $\begin{array}{l}\text { 5'-ATCGTGCATCCCTTTAGAGTGT-3' (forward) } \\
\text { 5'-GCTGTCAACGATACGCTACCTA-3' (reverse) }\end{array}$ \\
\hline MI0003140 & $\operatorname{miR}-512-3 p$ & $\begin{array}{l}\text { 5'-AAGTGCTGTCATAGCTGAGGTC-3' (forward) } \\
\text { 5'-GCTGTCAACGATACGCTACCTA-3' (reverse) }\end{array}$ \\
\hline MI0000070 & miR-16 & $\begin{array}{l}\text { 5'-CCAGTATTAACTGTGCTGCTGA-3' (forward) } \\
\text { 5'-GCTGTCAACGATACGCTACCTA-3' (reverse) }\end{array}$ \\
\hline MI0003153 & miR-523 & $\begin{array}{l}\text { 5'-GAACGCGCTTCCCTATAGAGGGT-3' (forward) } \\
\text { 5'-GCTGTCAACGATACGCTACCTA-3' (reverse) }\end{array}$ \\
\hline MI0000074 & $\operatorname{miR}-19 b$ & $\begin{array}{l}\text { 5'-TGTGCAAATCCATGCAAAACTGA-3' (forward) } \\
\text { 5'-GCTGTCAACGATACGCTACCTA-3' (reverse) }\end{array}$ \\
\hline MI0000439 & $\operatorname{miR}-23 b$ & $\begin{array}{l}\text { 5'-ATCACATTGCCAGGGATTACC-3' (forward) } \\
\text { 5'-GCTGTCAACGATACGCTACCTA-3' (reverse) }\end{array}$ \\
\hline MI0000083 & $\operatorname{miR}-26 a$ & $\begin{array}{l}\text { 5'-CCTATTCTTGGTTACTTGCACG-3' (forward) } \\
\text { 5'-GCTGTCAACGATACGCTACCTA-3' (reverse) }\end{array}$ \\
\hline
\end{tabular}

miRNA, microRNA; qRT-PCR, quantitative real-time PCR.

Total RNA quality analysis. A 260 to $280 \mathrm{~nm}$ absorbance ratio $(260 / 280)>1.8$ is usually considered to be an acceptable indicator of RNA purity for miRNA microarrays and indicates an absence of detectable protein contamination in the RNA sample (15). Following the extraction of total RNA from the samples, the 260/280 ratio of each extract was determined 
Table II. Comparison of the clinical characteristics of the infertile males with semen abnormalities and the healthy adult males.

\begin{tabular}{lcc}
\hline Parameter & $\begin{array}{c}\text { Infertile males } \\
(\mathrm{n}=86)\end{array}$ & $\begin{array}{c}\text { Healthy males } \\
(\mathrm{n}=86)\end{array}$ \\
\hline Age (years) & $32 \pm 1(27-41)$ & $32 \pm 2(29-42)$ \\
Volume $(\mathrm{ml})$ & $1.92 \pm 0.08(1-2)$ & 2 \\
Concentration $\left(10^{5} / \mathrm{ml}\right)$ & $97.59 \pm 18.05(24.0-224.7)$ & $57.37 \pm 13.17(39.0-117.4)$ \\
$\mathrm{a}+\mathrm{b}(\%)$ & $23.11 \pm 5.03(0-46.2)$ & $45.17 \pm 6.34(12.6-65.7)$ \\
$\mathrm{a}+\mathrm{b}+\mathrm{c}(\%)$ & $32.85 \pm 5.52(5.9-63.3)$ & $62.66 \pm 5.72(49.3-82.6)$ \\
\hline
\end{tabular}
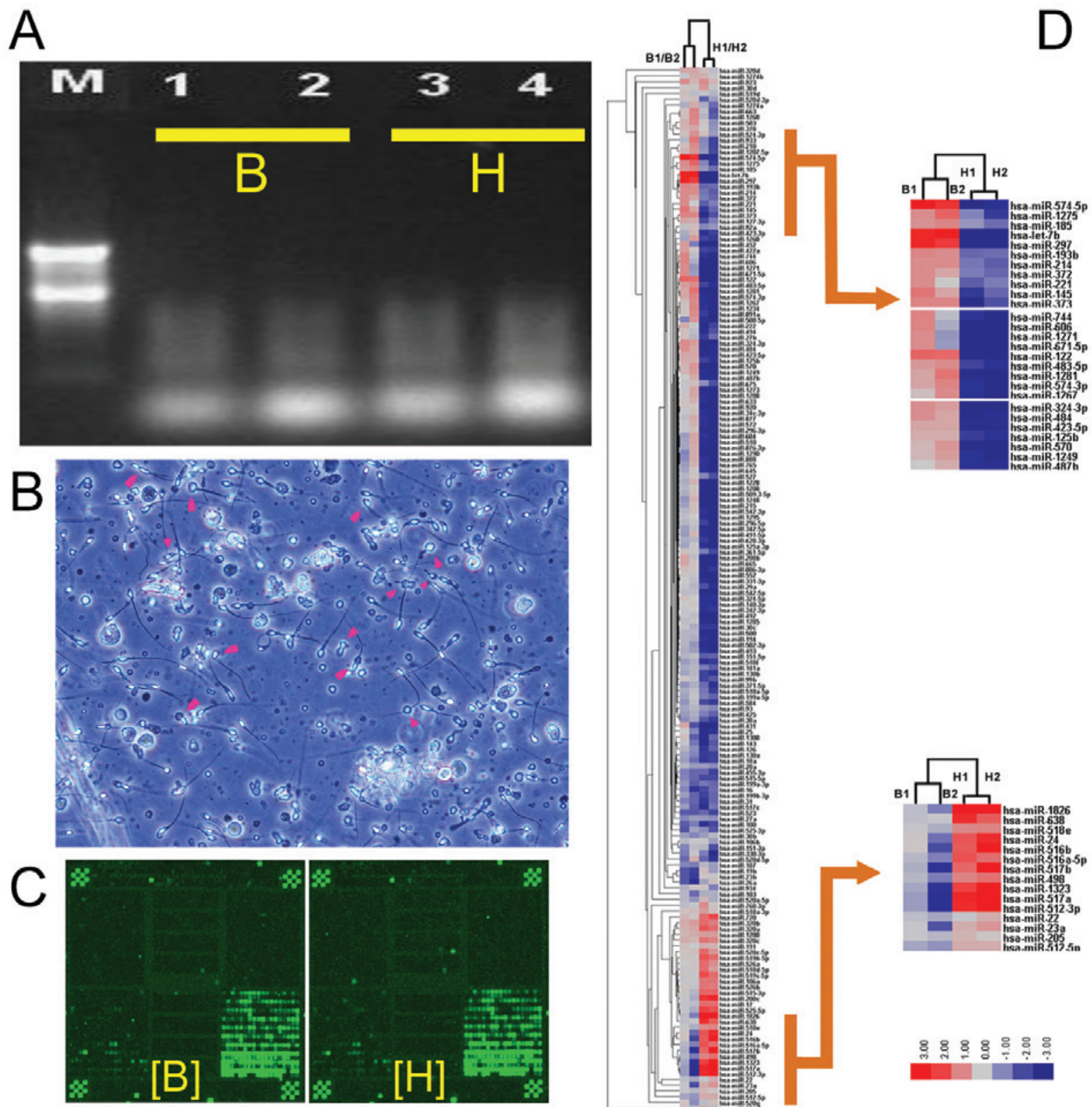

Figure 1. Differential miRNA expression patterns in the abnormal semen of infertile males and the semen of healthy adult males. (A) Gel electrophoresis analysis of semen total RNA. [B] is the sample from the 86 infertile males with semen abnormalities and $[\mathrm{H}]$ is the sample from the 86 healthy adult males. (B) Morphocytology of the abnormal semen from infertile males. Abnormal semen (arrows) and healthy semen were observed; original magnification x400. (C) Representative microarray hybridization signals for the RNA isolated from the abnormal semen of infertile males [B] and the normal semen of healthy adult males $[\mathrm{H}]$. The two subarrays of each microarray are marked, as well as the 16 controls and 2844 oligonucleotide probes. (D) miRNA microarray clustering tree (left) and sample clustering tree (top) for the 86 infertile males with semen abnormalities and the 86 healthy adult males. The same amount of total RNA was used on each slide, so the hybridization signals are normalized according to the total RNA concentration. The colour scale illustrates the miRNA expression levels across all samples: red denotes expression above the mean, blue denotes expression lower than the mean and grey represents a signal lower than the background. miRNA, microRNA. 
using a spectrophotometer $(15,31)$. The $260 / 280$ ratios ranged from 1.83 to 1.97 . Formaldehyde denaturing gel electrophoresis was used to confirm the presence of clear 28S, 18S and $5 \mathrm{~S}$ bands (Fig. 1) and the absence of marked RNA degradation. This analysis indicated that the purity and integrity of each RNA sample met the requirements of the miRNA microarray and qRT-PCR experiments (15).

miRNA microarray quality control and results analysis. In order to identify miRNAs which are differentially expressed between the abnormal semen of infertile males and the normal semen of healthy males, we prepared a miRNA microarray containing 2844 oligonucleotide probes (1823 human, 648 mouse and 373 rat) complementary to known mammalian miRNAs $(23,24,32)$. All probes were repeated three times in each microarray and each microarray contained 16 controls (Zip5, Zip13, Zip15, Zip21, Zip23, Zip25, Y2, Y3, U6, New-U2-R, tRNA-R, has-let-7a, has-let-7b, has-let-7c, $50 \%$ DMSO and Hex). In order to increase the reliability of the results, each miRNA microarray assay was repeated twice (24) and the scatter plots for all spots indicated that a high reproducibility and reliability were achieved (Fig. 2A).

The miRNA expression patterns for abnormal semen from infertile males (B) and normal semen from healthy males $(\mathrm{H})$ were compared. Significance analysis of microarray (SAM) and a fold change criterion $(\mathrm{B} / \mathrm{H}$ ratio) $>1.50$ or $<0.667$ and $\mathrm{p}<0.001$ were used to identify significant differences $(32,33)$. Using these criteria, we identified 52 miRNAs which were differentially expressed between the semen of infertile males and normal males. Analysis of the microarray expression levels confirmed that 21 miRNAs (mi-574-5p, let-7b, miR-297, miR-122, miR-1275, miR-1281, miR-373, miR-185, miR-193b, miR-145, miR-214, miR-574-3p, miR-483-5p, miR-324-3p, miR-372, miR-484, miR-933, miR-663, miR-1268, miR-923 and miR-1234) were significantly overexpressed in the abnormal semen compared with the normal semen. Conversely, 31 miRNAs (miR-1826, miR-493, miR-371-5p, miR-516a-5p, miR-512-5p, miR-498, miR-30a, miR-23a, miR-130a, miR-103, miR-30b, miR-27a, miR-18a, miR-525-3p, miR-517c, miR-199b-3p, miR-517b, miR-107, miR-199a-3p, miR-1323, miR-515-5p, miR-31, miR-455-3p, miR-100, miR-517a, miR-512-3p, miR-16, miR-523, miR-19b, miR-23b and miR-26a) were significantly underexpressed in the abnormal semen compared with the normal semen (Table III).

$q R T-P C R$ confirmation of the miRNA microarray results. Following common procedures for the confirmation of microarray analysis $(23,24,32-34)$, qRT-PCR was used to confirm the results of the miRNA microarray analysis. Of the 11 miRNAs identified by the microarray as being the most overexpressed in the abnormal semen of infertile males compared with normal semen (miR-574-5p, let-7b, miR-297, miR-122, miR-1275, miR-1281, miR-373, miR-185, miR-193b, miR-145 and miR-214), qRT-PCR confirmed that seven (miR-574-5p, miR-297, miR-122, miR-1275, miR-373, miR-185 and miR-193b) were overexpressed. Of the ten miRNAs identified as being underexpressed in abnormal semen by the microarray (miR-31, miR-455-3p, miR-100, miR-517a, miR-512-3p, miR-16, miR-523, miR-19b, miR-23b and miR-26a), the qRT-PCR analysis confirmed that six of these (miR-100, miR-512-3p, miR-16, miR-19b, miR-23b and miR-26a) were underexpressed.

Scatter plot analysis of the qRT-PCR results confirmed that seven miRNAs (miR-574-5p, miR-297, miR-122, miR-1275, miR-373, miR-185 and miR-193b) were overexpressed and six miRNAs (miR-100, miR-512-3p, miR-16, miR-19b, miR-23b and miR-26a) were underexpressed in the semen of infertile males compared with the normal semen (Fig. 2B).

A Venn diagram (Fig. 2C) was used to depict the correlation between the results of the miRNA microarray and the 21 miRNAs tested by qRT-PCR. The differential expression of 13 miRNAs (miR-574-5p, miR-297, miR-122, miR-1275, miR-373, miR-185, miR-193b, miR-100, miR-512-3p, miR-16, miR-19b, miR-23b and miR-26a) in the abnormal semen of the infertile males was confirmed by qRT-PCR (indicated by the overlap in the diagram). The expression levels of the other miRNAs correlated in some or other methods. Overall, the qRT-PCR analysis indicated that the miRNA microarray results had some small errors, however, it confirmed that a significant number of miRNAs are differentially regulated in the abnormal semen of infertile males.

Northern blot validation of miRNA expression. The expression levels of the 13 miRNAs which were confirmed to be differently expressed by qRT-PCR were further investigated by northern blotting of the RNA isolated from the abnormal semen of three infertile males and the normal semen of three healthy adult males. Anti-sense miRNA locked nucleic acid probes were used for each miRNA (Fig. 3). The northern blotting hybridization signals for miR-574-5p, miR-297, miR-122, miR-1275, miR-373, miR-185 and miR-193b were weaker in the semen of healthy adult controls than that of the infertile males, confirming that these miRNAs are upregulated in the abnormal semen. The miR-100, miR-512-3p, miR-16, miR-19b, miR-23b and miR-26a hybridization bands were barely detectable and, therefore, we could not confirm the differential regulation of these miRNAs using northern blotting.

\section{Discussion}

Mature miRNAs are an abundant class of 21-23 nt non-coding RNAs which regulate the expression of their target genes and are involved in many biological processes (15,21,23,24,32-34). To date, more than 1600 miRNAs have been identified in plants, animals and viruses $(16,21,35,36)$. It is currently estimated that miRNAs account for approximately $1 \%$ of all predicted genes and that up to $30 \%$ of the genes in higher eukaryotic genomes may be regulated by miRNAs (21); therefore, many miRNAs remain to be identified in mammalian genomes. Little is known concerning the patterns or levels of miRNA expression in the abnormal semen of infertile males $(24,33)$.

The aim of the study was to identify which miRNAs are differentially expressed between abnormal and normal sperm, in order to provide a foundation for future studies on the function and role of miRNAs in semen abnormalities. We profiled the expression of a number of miRNAs using a miRNA microarray and demonstrated that the expression of 52 miRNAs was significantly different in the abnormal semen of infertile males compared with the semen of healthy males. These results 
A.
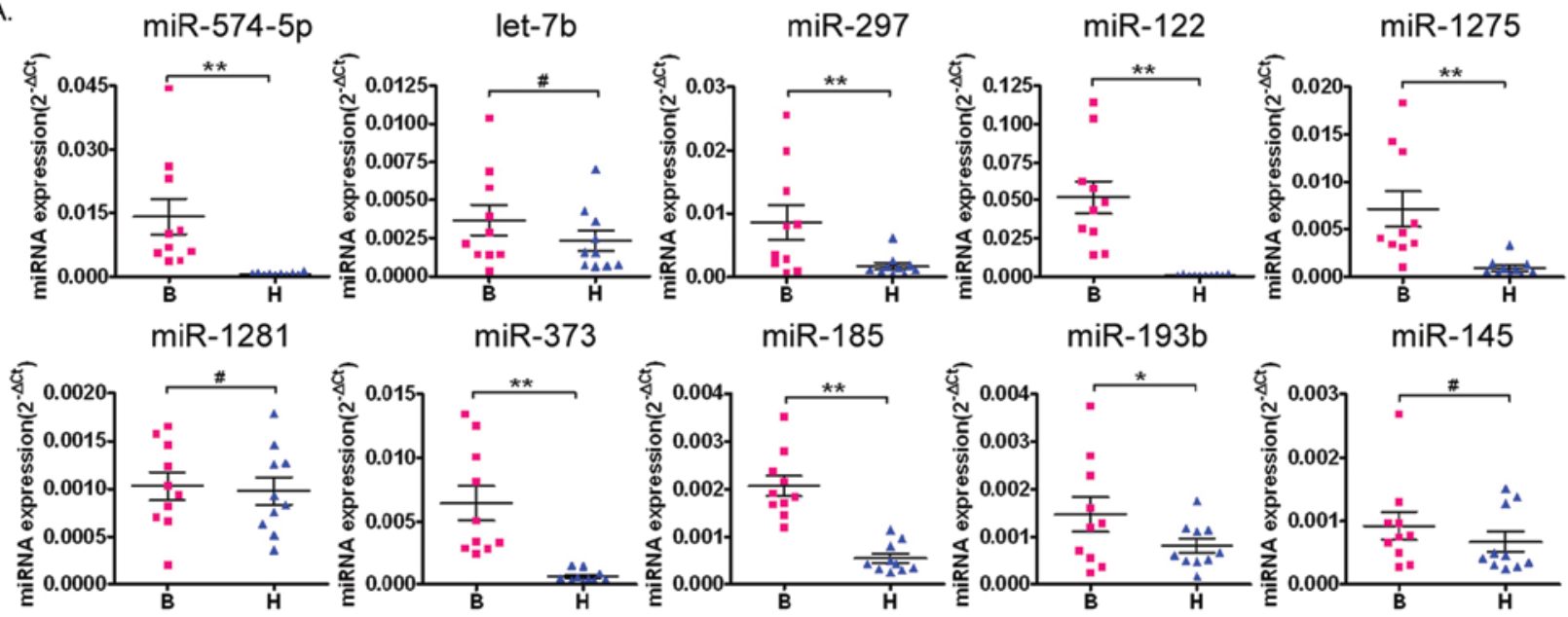

miR-185

miR-193b

miR-145
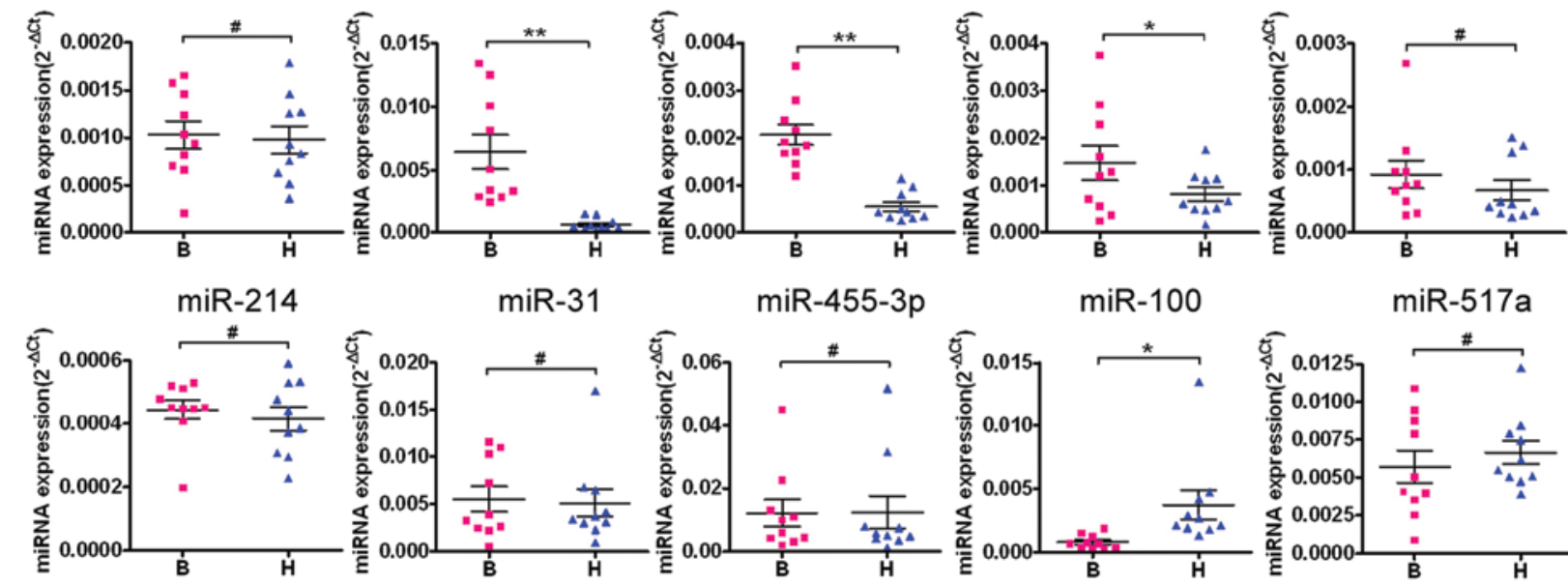

miR-455-3p

miR-100

$\operatorname{miR}-517 a$
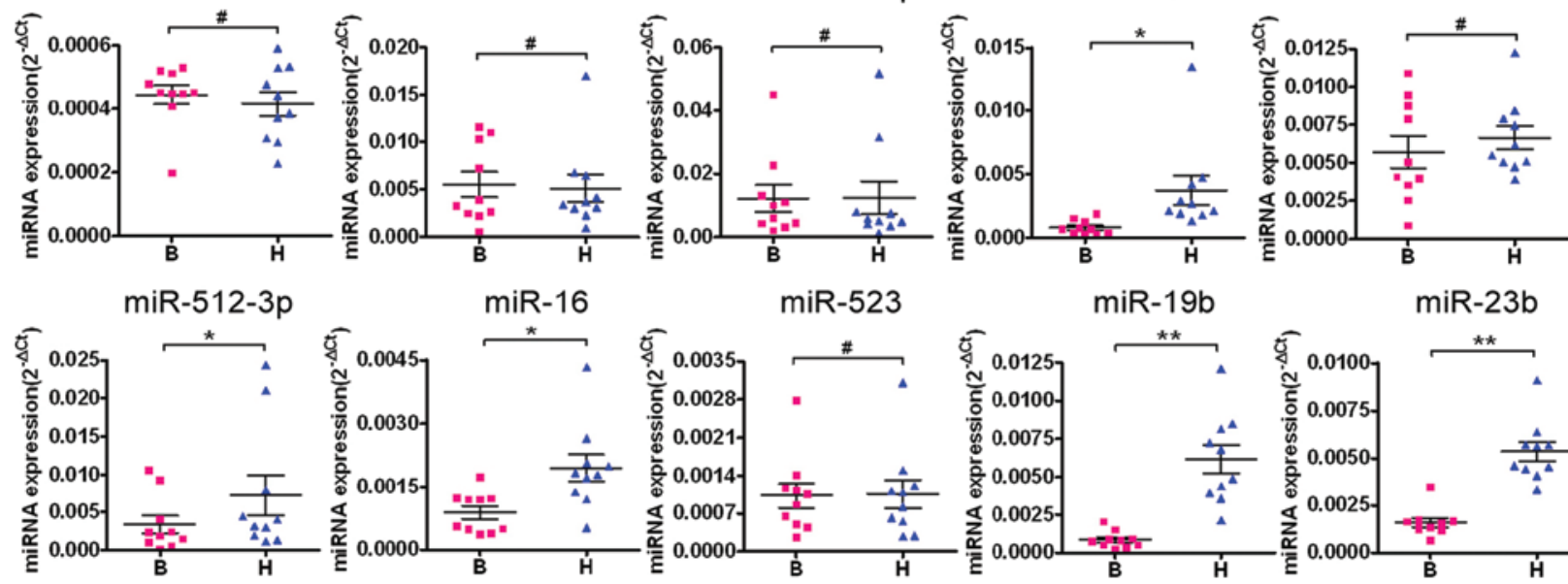

miR-523

miR-19b

miR-23b

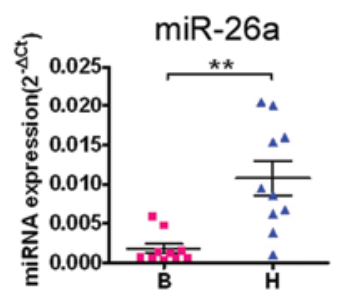

B.

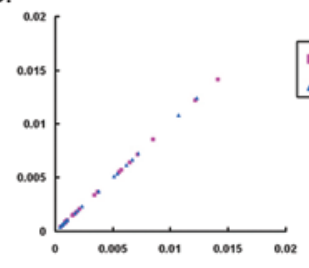

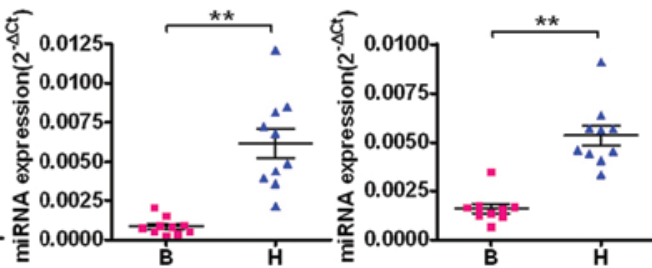

C. miRNA microarray

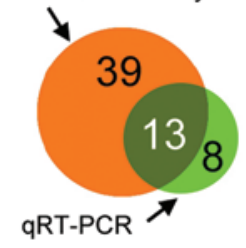

Figure 2. Confirmation of the differential expression of miRNAs in the abnormal semen from infertile males using qRT-PCR. (A) Scatter plots of the expression levels of miRNAs in the semen of 10 infertile males with semen abnormalities [B] and 10 healthy adult males [H] determined by qRT-PCR. Compared with the normal semen from healthy adult males, seven miRNAs were overexpressed and six miRNAs were underexpressed in abnormal semen. (B) Scatter plot showing the averaged background-subtracted raw intensity for each miRNA probe in the semen of 10 infertile males with semen abnormalities [B] and the normal semen of 10 healthy adult males [H]; each dot represents one miRNA probe. (C) Correlation between the microarray results and the qRT-PCR analysis. The 21 miRNAs which were identified by the microarray as being differentially expressed in the abnormal semen of infertile males were also tested by qRT-PCR. The differential expression of 13 miRNAs was confirmed by the two methods (overlap). The correlation was arbitrarily determined as a similar miRNA expression change in each assay. miRNA, microRNA; qRT-PCT, quantitative real-time PCR.

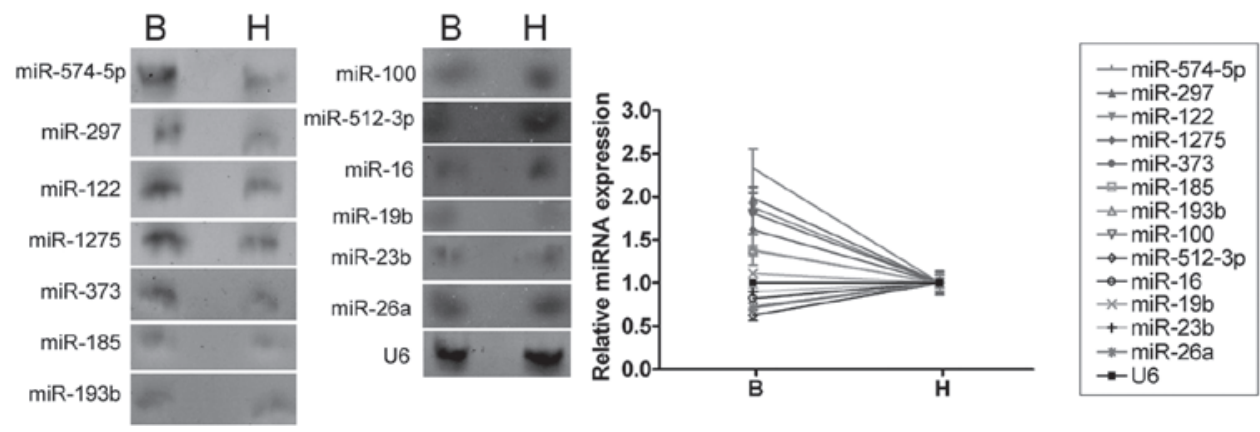

Figure 3. Northern blot analysis of the differential expression of miRNAs in abnormal semen from infertile men. Representative hybridization signals for the expression of the indicated miRNAs in abnormal semen from infertile males [B] and normal semen from healthy adult males [H]. 
Table III. Summary of the SAM results for miRNA expression in the abnormal semen of infertile males and the normal semen of healthy adult males.

\begin{tabular}{|c|c|c|c|c|}
\hline miRNA & $\begin{array}{l}\text { Fold change } \\
\qquad(\mathrm{B} / \mathrm{H})\end{array}$ & Mature miRNA sequence & $\begin{array}{l}\text { Chromosome } \\
\text { location }\end{array}$ & $\begin{array}{c}\text { Sequence length } \\
\text { (nt) }\end{array}$ \\
\hline $\operatorname{miR}-574-5 p$ & 7.0715 & UGAGUGUGUGUGUGUGAGUGUGU & 4 & 23 \\
\hline let-7b & 5.7958 & UGAGGUAGUAGGUUGUGUGGUU & 22 & 22 \\
\hline miR-297 & 4.8753 & AUGUAUGUGUGCAUGUGCAUG & 4 & 21 \\
\hline miR-122 & 2.7916 & UGGAGUGUGACAAUGGUGUUUG & 18 & 22 \\
\hline $\operatorname{miR}-1275$ & 2.3772 & GUGGGGGAGAGGCUGUC & 6 & 17 \\
\hline $\operatorname{miR}-1281$ & 1.9876 & UCGCCUCCUCCUCUCCC & 22 & 17 \\
\hline $\operatorname{miR}-373$ & 1.9799 & GAAGUGCUUCGAUUUUGGGGUGU & 19 & 23 \\
\hline miR-185 & 1.9584 & UGGAGAGAAAGGCAGUUCCUGA & 22 & 22 \\
\hline miR-193b & 1.9558 & AACUGGCCCUCAAAGUCCCGCU & 16 & 22 \\
\hline miR-145 & 1.9218 & GUCCAGUUUUCCCAGGAAUCCCU & 5 & 23 \\
\hline $\operatorname{miR}-214$ & 1.9027 & ACAGCAGGCACAGACAGGCAGU & 1 & 22 \\
\hline miR-574-3p & 1.7689 & CACGCUCAUGCACACACCCACA & 4 & 22 \\
\hline $\operatorname{miR}-483-5 p$ & 1.7640 & AAGACGGGAGGAAAGAAGGGAG & 11 & 22 \\
\hline $\operatorname{miR}-324-3 p$ & 1.7295 & ACUGCCCCAGGUGCUGCUGG & 17 & 20 \\
\hline miR-372 & 1.7001 & AAAGUGCUGCGACAUUUGAGCGU & 19 & 23 \\
\hline $\operatorname{miR}-484$ & 1.6988 & UCAGGCUCAGUCCCCUCCCGAU & 16 & 22 \\
\hline miR-933 & 1.6101 & UGUGCGCAGGGAGACCUCUCCC & 2 & 22 \\
\hline $\operatorname{miR}-663$ & 1.6083 & AGGCGGGGCGCCGCGGGACCGC & 20 & 22 \\
\hline $\operatorname{miR}-1268$ & 1.6016 & CGGGCGUGGUGGUGGGGG & 15 & 18 \\
\hline miR-923 & 1.5892 & GUCAGCGGAGGAAAAGAAACU & 17 & 21 \\
\hline $\operatorname{miR}-1234$ & 1.5736 & UCGGCCUGACCACCCACCCCAC & 8 & 22 \\
\hline $\operatorname{miR}-1826$ & 0.6548 & AUUGAUCAUCGACACUUCGAACGCAAU & 16 & 27 \\
\hline miR-493 & 0.6536 & UGAAGGUCUACUGUGUGCCAGG & 14 & 22 \\
\hline miR-371-5p & 0.6517 & ACUCAAACUGUGGGGGCACU & 19 & 20 \\
\hline $\operatorname{miR}-516 a-5 p$ & 0.6441 & UUCUCGAGGAAAGAAGCACUUUC & 19 & 23 \\
\hline $\operatorname{miR}-512-5 p$ & 0.6322 & CACUCAGCCUUGAGGGCACUUUC & 19 & 23 \\
\hline $\operatorname{miR}-498$ & 0.6191 & UUUCAAGCCAGGGGGCGUUUUUC & 19 & 23 \\
\hline miR-30a & 0.6070 & UGUAAACAUCCUCGACUGGAAG & 6 & 22 \\
\hline miR-23a & 0.6058 & AUCACAUUGCCAGGGAUUUCC & 19 & 21 \\
\hline miR-130a & 0.5913 & CAGUGCAAUGUUAAAAGGGCAU & 11 & 22 \\
\hline miR-103 & 0.5886 & AGCAGCAUUGUACAGGGCUAUGA & 20 & 23 \\
\hline $\mathrm{miR}-30 \mathrm{~b}$ & 0.5771 & UGUAAACAUCCUACACUCAGCU & 8 & 22 \\
\hline $\operatorname{miR}-27 \mathrm{a}$ & 0.5577 & UUCACAGUGGCUAAGUUCCGC & 19 & 21 \\
\hline $\operatorname{miR}-18 \mathrm{a}$ & 0.4980 & UAAGGUGCAUCUAGUGCAGAUAG & 13 & 23 \\
\hline $\operatorname{miR}-525-3 p$ & 0.4817 & GAAGGCGCUUCCCUUUAGAGCG & 19 & 22 \\
\hline $\operatorname{miR}-517 \mathrm{c}$ & 0.4783 & AUCGUGCAUCCUUUUAGAGUGU & 19 & 22 \\
\hline $\operatorname{miR}-199 b-3 p$ & 0.4700 & ACAGUAGUCUGCACAUUGGUUA & 9 & 22 \\
\hline $\operatorname{miR}-517 b$ & 0.4672 & UCGUGCAUCCCUUUAGAGUGUU & 19 & 22 \\
\hline $\operatorname{miR}-107$ & 0.4641 & AGCAGCAUUGUACAGGGCUAUCA & 19 & 23 \\
\hline $\operatorname{miR}-199 a-3 p$ & 0.4452 & ACAGUAGUCUGCACAUUGGUUA & 19 & 22 \\
\hline $\operatorname{miR}-1323$ & 0.4352 & UCAAAACUGAGGGGCAUUUUCU & 19 & 22 \\
\hline $\operatorname{miR}-515-5 p$ & 0.4279 & UUCUCCAAAAGAAAGCACUUUCUG & 19 & 24 \\
\hline $\operatorname{miR}-31$ & 0.4137 & AGGCAAGAUGCUGGCAUAGCU & 9 & 21 \\
\hline $\operatorname{miR}-455-3 p$ & 0.4117 & GCAGUCCAUGGGCAUAUACAC & 9 & 21 \\
\hline miR-100 & 0.3938 & AACCCGUAGAUCCGAACUUGUG & 11 & 22 \\
\hline $\operatorname{miR}-517 a$ & 0.3889 & AUCGUGCAUCCCUUUAGAGUGU & 19 & 22 \\
\hline $\operatorname{miR}-512-3 p$ & 0.3884 & AAGUGCUGUCAUAGCUGAGGUC & 19 & 22 \\
\hline $\operatorname{miR}-16$ & 0.3455 & UAGCAGCACGUAAAUAUUGGCG & 13 & 22 \\
\hline $\operatorname{miR}-523$ & 0.3075 & GAACGCGCUUCCCUAUAGAGGGU & 19 & 23 \\
\hline miR-19b & 0.2670 & UGUGCAAAUCCAUGCAAAACUGA & 13 & 23 \\
\hline $\operatorname{miR}-23 b$ & 0.2616 & AUCACAUUGCCAGGGAUUACC & 9 & 21 \\
\hline miR-26a & 0.2221 & UUCAAGUAAUCCAGGAUAGGCU & 12 & 22 \\
\hline
\end{tabular}

SAM, significance analysis of microarray; $\mathrm{B} / \mathrm{H}$, ratio of miRNA expression in the abnormal semen of infertile males [B] to that in the normal semen of healthy adult males $[\mathrm{H}]$. 
suggest that miRNAs are involved in the development of male infertility associated with semen abnormalities.

We used qRT-PCR to confirm the expression levels of 21 of the 52 miRNAs which were differentially expressed in the microarray. In total, 13 of the 21 miRNAs tested were identified as being differentially expressed in abnormal semen by the microarray and qRT-PCR. Although, there were some discrepancies in the results of the microarray and the qRT-PCR analysis, the miRNA microarray provided a rapid method for identifying a large number of differentially expressed miRNAs in abnormal semen which could then be confirmed by qRT-PCR.

This study describes the global expression patterns of miRNAs in the abnormal semen from infertile males and contributes to the growing understanding of the role of miRNAs in the development of semen abnormalities. Moreover, the differential expression patterns of miRNAs between normal and abnormal semen may enable the direct diagnosis of semen abnormalities or provide novel therapeutic targets for infertile males.

\section{Acknowledgements}

This study was supported by a grant from the Shanghai Committee Medical Science Foundation of China (No. 10411967100) to Te Liu.

\section{References}

1. Zenzmaier C, Gerth R, Gruschwitz M, Lindner H, Plas E and Berger P: Decreased levels of genuine large free hCG alpha in men presenting with abnormal semen analysis. Reprod Biol Endocrinol 9: 114, 2011.

2. Hu W, Yang H, Sun J, et al: Polymorphisms in CYP1B1 modify the risk of idiopathic male infertility with abnormal semen quality. Clin Chim Acta 412: 1778-1782, 2011.

3. Chatzimeletiou K, Sioga A, Oikonomou L, et al: Semen analysis by electron and fluorescence microscopy in a case of partial hydatidiform mole reveals a high incidence of abnormal morphology, diploidy, and tetraploidy. Fertil Steril 95: e2431-e2435, 2011.

4. Moretti E, Castellini C, Mourvaki E, et al: Distribution of $\alpha$ and $\delta$-tocopherols in seminal plasma and sperm fractions of men with normal and abnormal semen parameters. J Androl 32: 232-239, 2011.

5. Kowalczuk CI, Saunders RD and Stapleton HR: Sperm count and sperm abnormality in male mice after exposure to $2.45 \mathrm{GHz}$ microwave radiation. Mutat Res 122: 155-161, 1983.

6. Narayana K, Prashanthi N, Nayanatara A, Kumar HH, Abhilash K and Bairy KL: Effects of methyl parathion (O,O-dimethyl O-4-nitrophenyl phosphorothioate) on rat sperm morphology and sperm count, but not fertility, are associated with decreased ascorbic acid level in the testis. Mutat Res 588: 28-34, 2005.

7. Padmalatha Rai S and Vijayalaxmi KK: Tamoxifen citrate induced sperm shape abnormalities in the in vivo mouse. Mutat Res 492: 1-6, 2001.

8. Calogero AE, De Palma A, Grazioso C, et al: Aneuploidy rate in spermatozoa of selected men with abnormal semen parameters. Hum Reprod 16: 1172-1179, 2001.

9. Jacobsen R, Bostofte E, Engholm G, et al: Risk of testicular cancer in men with abnormal semen characteristics: cohort study. BMJ 321: 789-792, 2000.

10. Torra R, Sarquella J, Calabia J, et al: Prevalence of cysts in seminal tract and abnormal semen parameters in patients with autosomal dominant polycystic kidney disease. Clin J Am Soc Nephrol 3: 790-793, 2008.

11. Ravnborg TL, Jensen TK, Andersson AM, Toppari J, Skakkebaek NE and Jørgensen N: Prenatal and adult exposures to smoking are associated with adverse effects on reproductive hormones, semen quality, final height and body mass index. Hum Reprod 26: 1000-1011, 2011.
12. Barratt CL, Björndahl L, Menkveld R and Mortimer D: ESHRE special interest group for andrology basic semen analysis course: a continued focus on accuracy, quality, efficiency and clinical relevance. Hum Reprod 26: 3207-3212, 2011.

13. Sumazin P, Yang X, Chiu HS, et al: An extensive microRNA-mediated network of RNA-RNA interactions regulates established oncogenic pathways in glioblastoma. Cell 147: 370-381, 2011.

14. Poulton JS, Huang YC, Smith L, et al: The microRNA pathway regulates the temporal pattern of Notch signaling in Drosophila follicle cells. Development 138: 1737-1745, 2011.

15. Lei P, Li Y, Chen X, Yang S and Zhang J: Microarray based analysis of microRNA expression in rat cerebral cortex after traumatic brain injury. Brain Res 1284: 191-201, 2009.

16. Bartel DP: MicroRNAs: genomics, biogenesis, mechanism, and function (Review). Cell 116: 281-297, 2004.

17. Yoo AS, Sun AX, Li L, et al: MicroRNA-mediated conversion of human fibroblasts to neurons. Nature 476: 228-231, 2011.

18. Dai Y, Diao Z, Sun H, Li R, Qiu Z and Hu Y: MicroRNA-155 is involved in the remodelling of human-trophoblast-derived HTR-8/SVneo cells induced by lipopolysaccharides. Hum Reprod 26: 1882-1891, 2011.

19. He L and Hannon GJ: MicroRNAs: small RNAs with a big role in gene regulation (Review). Nat Rev Genet 5: 522-531, 2004.

20. El Ouaamari A, Baroukh N, Martens GA, Lebrun P, Pipeleers D and van Obberghen E: miR-375 targets 3'-phosphoinositidedependent protein kinase- 1 and regulates glucose-induced biological responses in pancreatic beta-cells. Diabetes 57 : 2708-2717, 2008

21. Yang Y, Bai W, Zhang L, et al: Determination of microRNAs in mouse preimplantation embryos by microarray. Dev Dyn 237: 2315-2327, 2008

22. Calin GA, Liu CG, Sevignani C, et al: MicroRNA profiling reveals distinct signatures in $B$ cell chronic lymphocytic leukemias. Proc Natl Acad Sci USA 101: 11755-11760, 2004.

23. Bloomston M, Frankel WL, Petrocca F, et al: MicroRNA expression patterns to differentiate pancreatic adenocarcinoma from normal pancreas and chronic pancreatitis. JAMA 297: 1901-1908, 2007.

24. Yan N, Lu Y, Sun H, et al: A microarray for microRNA profiling in mouse testis tissues. Reproduction 134: 73-79, 2007.

25. Wang LL, Zhang Z, Li Q, et al: Ethanol exposure induces differential microRNA and target gene expression and teratogenic effects which can be suppressed by folic acid supplementation. Hum Reprod 24: 562-579, 2009.

26. Barshack I, Meiri E, Rosenwald S, et al: Differential diagnosis of hepatocellular carcinoma from metastatic tumors in the liver using microRNA expression. Int J Biochem Cell Biol 42: 1355-1362, 2010

27. Li W, Xie L, He X, et al: Diagnostic and prognostic implications of microRNAs in human hepatocellular carcinoma. Int J Cancer 123: 1616-1622, 2008.

28. Cheng W, Liu T, Jiang F, et al: microRNA-155 regulates angiotensin II type 1 receptor expression in umbilical vein endothelial cells from severely pre-eclamptic pregnant women. Int J Mol Med 27: 393-399, 2011.

29. Zhang L, Liu T, Huang Y and Liu J: microRNA-182 inhibits the proliferation and invasion of human lung adenocarcinoma cells through its effect on human cortical actin-associated protein. Int J Mol Med 28: 381-388, 2011.

30. Li S, Chen X, Zhang H, et al: Differential expression of microRNAs in mouse liver under aberrant energy metabolic status. J Lipid Res 50: 1756-1765, 2009.

31. Wang WX, Wilfred BR, Baldwin DA, et al: Focus on RNA isolation: obtaining RNA for microRNA (miRNA) expression profiling analyses of neural tissue. Biochim Biophys Acta 1779: 749-757, 2008.

32. Liu HH, Tian X, Li YJ, Wu CA and Zheng CC: Microarray-based analysis of stress-regulated microRNAs in Arabidopsis thaliana. RNA 14: 836-843, 2008.

33. Wu H, Neilson JR, Kumar P, et al: miRNA profiling of naive, effector and memory CD8 T cells. PLoS One 2: e1020, 2007.

34. Kuhn DE, Nuovo GJ, Martin MM, et al: Human chromosome 21-derived miRNAs are overexpressed in down syndrome brains and hearts. Biochem Biophys Res Commun 370: 473-477, 2008.

35. Ambros V: The functions of animal microRNAs (Review). Nature 431: 350-355, 2004.

36. Du T and Zamore PD: microPrimer: the biogenesis and function of microRNA (Review). Development 132: 4645-4652, 2005. 